From the Editor-in-Chief

\title{
Speaking Up, Questioning Assumptions About Racism
}

\author{
Lori Wiviott Tishler, MD, MPH
}

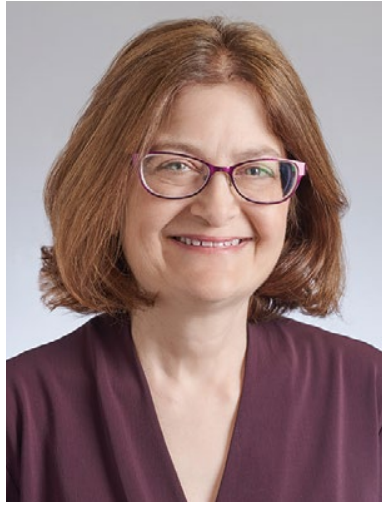

Dr. Tishler is Senior Vice President of Medical Services for Commonwealth Care Alliance, Boston, MA.

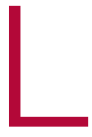
et me start with these 3 words that really should never have to be said: Black Lives Matter.

It was hard to sit down to write this piece-not just because it's a sunny Sunday morning, but because l'm still afraid I'll get it wrong, show my white privilege, offend someone. George Floyd's murder has been a reckoning for Black Americans, for the police, for the nation (maybe the world), and for me. I live in a multi-racial household, and we have redoubled our efforts to talk about racism and bias and question our assumptions as part of our daily conversations. After Mr. Floyd was killed, I decided that I would try to be less afraid of getting it wrong and be more outspoken about my support for Black Lives Matter and for the work that we need to do in this country, and in ourselves, to become more antiracist.

Here are some things that I know: I know that study after study has shown that health care and health outcomes are worse for Black people than for White people. I know that people of color are sickening and dying with COVID-19 before our eyes, just as other pandemics, such as HIV, differentially affect communities of color. I know, too, that a Black physician executive who lives around the corner from me has been stopped by our local police more than 10 times; I have been stopped by our local police exactly once.

I don't know how to fix it. But I do know that my silence won't help. Here are some things I am trying to do at home and at work: I am educating myself about race and racism. I'm not asking my Black peers, patients, or colleagues to teach me, but I am listening to what they tell me, when they want to tell me. I am reading books like Ibram Kendi's How to Be Antiracist and Bernadine Evaristo's Girl, Woman, Other. I challenge myself to read articles that I might have skipped over-because they were simply too painful. People of color don't have a choice about facing their pain. I have that choice-it's a privilege-and I choose to be an ally.

I'm speaking up even when I'm afraid that I might say the wrong thing. This can take several forms-questioning assumptions about race and racism when it comes up, which is often, in medicine. It also means amplifying the voices that don't always get heard-asking a young person of color her opinion in a meeting, retweeting the thoughts of a Black colleague, thanking someone publicly or personally for a comment, an idea, or the kernel of something important. I ask people to correct me, and I try to be humble in accepting criticism or correction.

Being a better ally also means putting our money where our mouth is, supporting Black-owned businesses and restaurants, and donating to causes that support equality and justice. We can diversify our social media feeds. We have to be willing to be excluded from the conversation-if you're white or straight or cis-gendered, it's not about you-and be ready to feel uncomfortable. We can encourage our organizations to do better. I'm proud of my organization, which had already started working to make our organizational culture even more inclusive.

Black Lives Matter. I'm looking forward to a day when that is so obvious that we don't have to say it. Until then, I'm going to be hard at work with my head, my ears, and my whole heart. 